\title{
Design A Smart Reservation for Parking System
}

\author{
Noora A. Salim \\ nooraammarsalim@uomosul.edu.iq \\ Manar Y. Kashmoola \\ manar.kashmola@uomosul.edu.iq \\ Department of Computer Science \\ College of Computer Science and Mathematics \\ University of Mosul, Mosul, Iraq
}

Received on: 25/01/2021

Accepted on: 23/03/2021

\begin{abstract}
Nowadays, the smartphone device has become the most used device for the convenience of the user, smart parking is one such application that helps the consumer to find car parking space in an urban area. Mosul University, in particular, is one of these places. Common problems are the lack of information about vacant parking spaces and there is no way to search for them online. The goal of this work is to produce an Android and iOS app that uses ultrasonic sensors connected to the Arduino MEGA 2560 microcontroller to send parking occupancy values to cloud, in an online database executed using Google Firebase. Finally, this application can book and pay online.
\end{abstract}

Keywords :Online Parking Booking, Arduino, ultrasonic sensor, QR code, IoT.

\section{Introduction}

In the past few years, the Iraqi government has implemented electronic services to provide fast and high-quality services to citizens [11]. Mobile applications play an important role in public sector services [1]. Moreover, it can also apply to the private sector like smart car parks. Currently, most of the existing car parks do not have a regular system. Most of them are manually controlled and less efficient. The problem that occurs constantly in the parking lot is wasting time trying to find parking spaces [5]. Finding a suitable parking lot is one of the most difficult problems today in general in the urban country, especially in universities. Less attention has been given to arrange parking lots within universities in any city in Iraq [4] .Traffic congestion caused by a large number of vehicles is a very big problem in major cities. Almost every global city in the world suffers from traffic congestion, which frustrates drivers especially when searching for a parking space. Solving such a problem or perhaps trying to alleviate it will surely offer many benefits, such as reducing driver frustration and pressure by saving time and fuel, and reducing gas emissions, which will affect pollution levels respectively [12][8].The large deployment of wireless parking meters with parking sensor and connectivity allows for the detection and monitoring of each parking space in real time and improved parking management [15]. Using low-cost sensors, real-time data collection, and mobile-phone-enabled automated payment systems that allow people to reserve parking in advance or very accurate predict where they will likely find a spot. When deployed as a system, smart parking thus reduces car emissions in urban centers by reducing the need to search for parking [16]. The purpose of this thesis is to investigate parking problems on campus to meet drivers' requirements. Therefore, ultrasound sensors will be used to investigate whether spaces are empty or full. In this thesis, Arduino Mega was used as the OPBS controller. The Online Parks Booking System (OPBS) plays an important role nowadays, to improve parking services for motorists. There are many different systems that can be used in SBS to develop parking 
services in cities, malls, universities and organizations by providing parking data control and monitoring parking activities, we propose an idea to realize Smart Parking structure in perspective of Booking using Internet of Things (IoT).

The design architecture of the Smart Booking System is illustrated in the following Figure 1 and Figure 2.

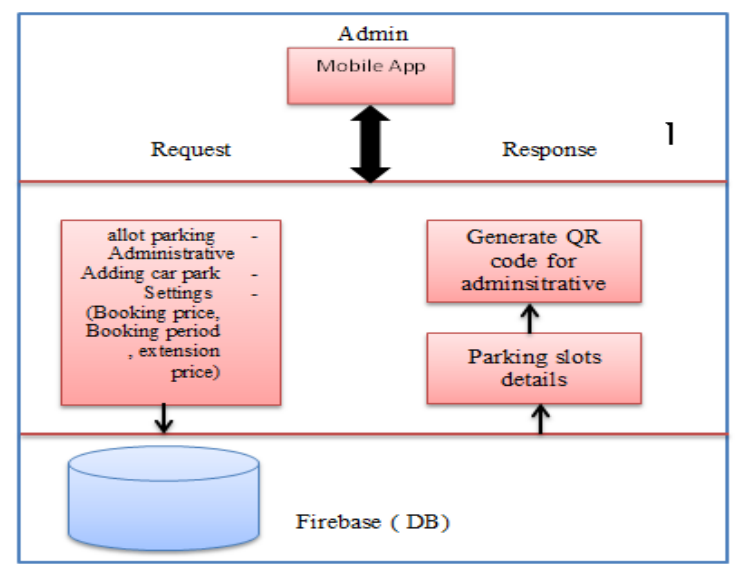

Fig.1: Admin API

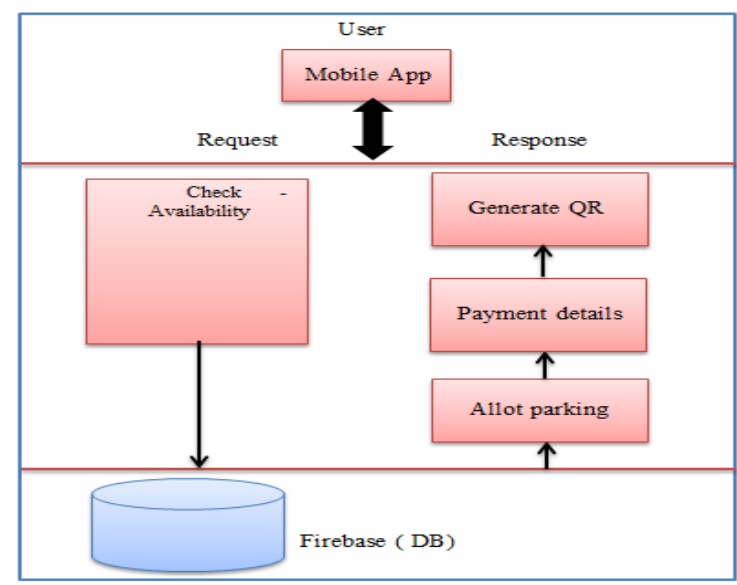

Fig.2 : User API

\section{Related Works}

In 2011 Hongwei Wang exploited Bluetooth and Zigbee sensors, a Bluetooth communication technique for verifying the driver's identity and also to book a slot by identifying the vacant spaces, Zigbee sensors to detect the vehicle. The proposed approach proved that the Internet usage is not necessary[10]. In 2015, T. N. Pham presented a framework for a cloud-based smart parking system the usage of the Internet of Things concept the data is transferred to the information center on the cloud. This information consists of the car's GPS region, the gap between the parking vicinity within the network and the free space in every parking area. Use RFID tags to authenticate consumer information and check vacant parking spaces in every parking vicinity[9]. In 2017 Supriya, et al. Proposed a system which used Google map implementation. Ultrasonic sensor and data gathered are stored in cloud. Android application map offers consumer friendly information regarding vacant area.Each slot has one LED display which assist to discover the right parking area[14] .In 2018 year, Qadir, et al., they presented IoT based smart parking that the solution consist of Microcontroller Arduino with ZigBee are used for real time notifications relating to parking slot tenancy or non- tenancy and navigation to target is provided to driver through android based application[7]. In 2019 Marso, et al., designed a hardware system using Arduino, RPI, Ultrasonic Sensor, IR Sensor. The proposed system will be able to detect whether a parking space is occupied or not, and where the data are available for drivers using the proposed Android application for finding free parking spaces. The benefits of the proposed system is that it is Android App [6]. In the same year, Balhwan, et al., they proposed RPi board and ultrasonic sensor for IoT based smart parking. Information are sent wirelessly to the cloud for storage. The data from the cloud is accessed by the user with the help of android application. User can view this information [3].

The defects for these systems are no reservation, no online payment method compared with these works. A different solution which takes the advantage of new technology (Firebase) was used to improve performance and reliability.Arduino board, 
ultrasonic sensor, QR for IoT based smart parking Furthermore, the Booking and Payment will be Online through the designed Android and iOS application.

\section{Technological Background}

\subsection{Arduino MEGA2560 microcontroller}

The Arduino Mega has an onboard ATmega2560 microcontroller. It has USB connection, 4 UART, an energy jack, and a reset button, 16 analog inputs, 54 digital I/Os. It operates on $16 \mathrm{MHz}$ frequency. Figure 3, and the Arduino microcontroller programmed with the aid of Arduino software (desktop IDE) using C programming language, and its circuit.

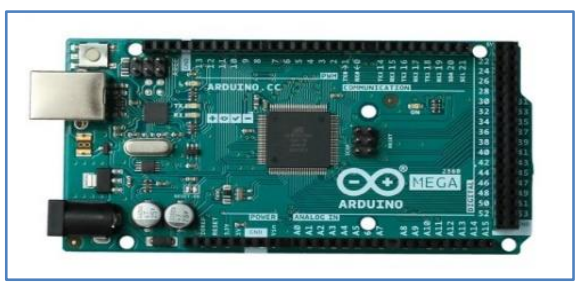

Fig. 3: Arduino Mega board

\subsection{Ultrasonic Sensor HC-SR04}

The modules consist of Ultrasonic transmitter, receiver and control unit. Four pins of the ultrasonic sensor that is GND, TRIGGER, ECHO and VCC.[2]. As in Figure 4

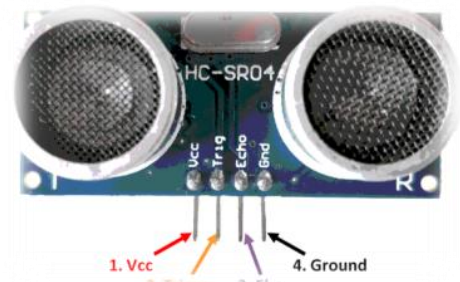

Fig. 4: ultrasonic sensor HC-sr04

It detects the objects, then measuring the distance between the object and the sensor by the website.

\section{3 servo motor}

It is a device that has a rotating axis. This axis will be linked to parts that require to move at a certain angle, this kind leads to movement and rotation forward or backward at an angle (180 degrees or 90 degrees) [13]. Arduino gives commands to the servo motor to start out or stop. this manner it controls the parking gate. As in Figure 5.

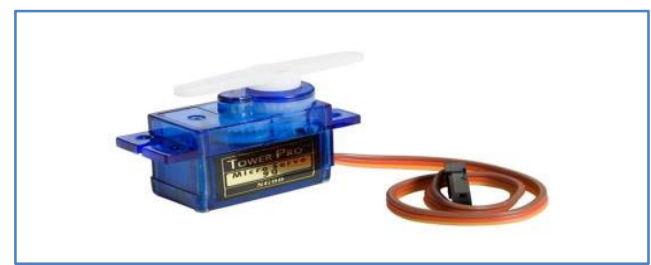

Fig.5: Servo Motor

\subsection{Arduino MEGA2560 microcontroller circuit}

The website https://www.tinkercad.com are used to design Arduino MEGA 2560 microcontroller circuit, and virtually tested using Arduino Uno because there is no 
Arduino Mega for test, anyway, it's same Mega version in implementation. See Figure 6.

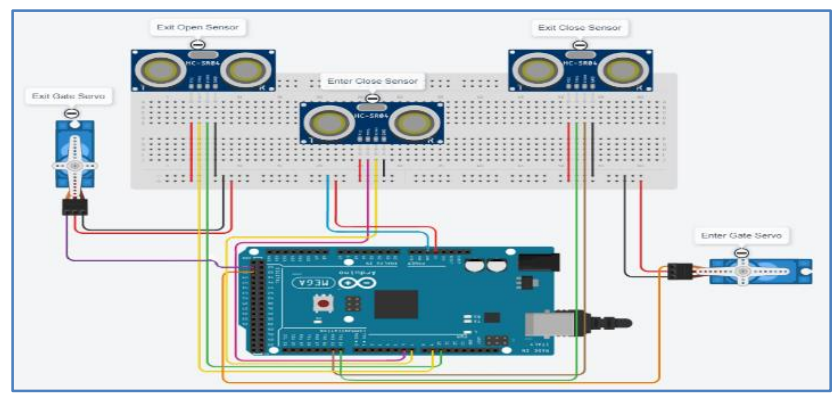

Fig.6: Arduino MEGA 2560 microcontroller circuit

\section{The Proposed System}

The introduced Android and iOS application consists of eight pages:

1- Login page: This page for create a new account.

2- Main page: This page will show "How to use instructions".

3- Park details page: This page displays park information like park name, address, capacity, reserved parks, remaining parks, and button named Booking "حجز to reserve a park online.

4- Menu page: This page displays a list of items and header contains some of user information like profile picture, user full name, and balance, etc..,.

5- Favorite page: It is displaying a list of cards selected as favorite park.

6- Parks on maps page: This page displays a map with all parks, each park marked with red pin.

7- About page: displays application and author details.

8- Logout: This page When the user logs out from the application.

The mobile application is called "OPBA" it enables users to locate any car parking space. The app is available on android and iOS, it is implemented using C\# programming language under Microsoft .NET Standard version 2.1 and Xamarin version 16.6 platform with the aid of Microsoft Visual Studio 2019 (Community) as IDE., and Google Map API is used to show Google map in the app. Parking types as well as Google map settings can be changed on this app. Figure 7 and Figure 8 and Figure 9 shows the mobile application interface. 


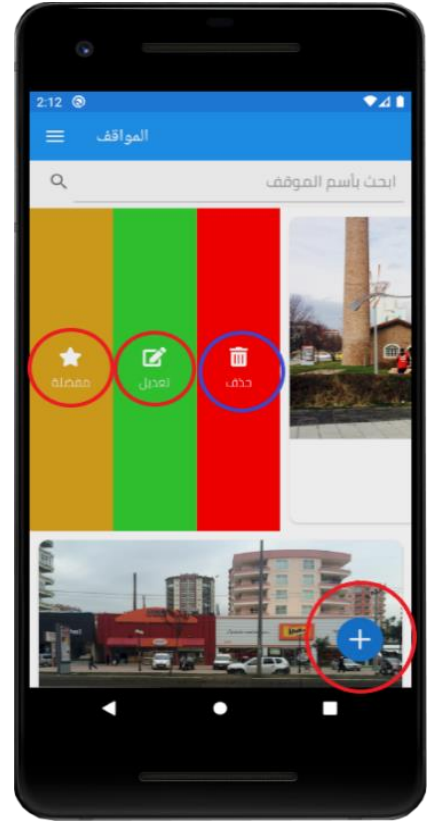

Fig. 7: Admin Main page

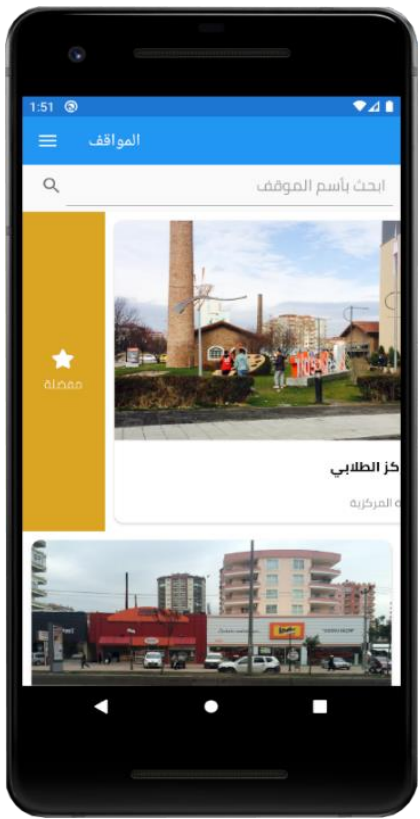

Fig. 8: User Main page

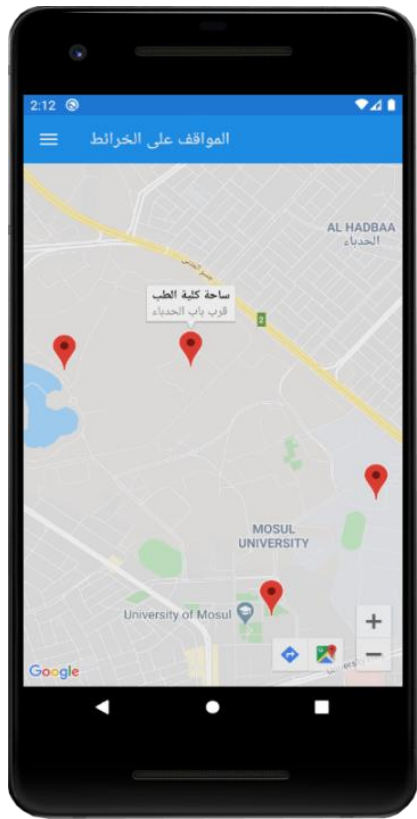

Fig. 9: Parks on maps page

\section{Implementation of Online Parks Booking Application}

This part of system is implemented using C\# programming language under Microsoft .NET Standard version 2.1 and Xamarin version 16.6 platform with the aid of Microsoft Visual Studio 2019 (Community) as IDE. Large number of libraries were used, some of them are $3^{\text {rd }}$ party such as ZXing to generate QR code, Xamarin.FFImageLoading to load images quickly and easily, ImageCropper.Forms.Fix.v2 to import and crop images from mobile gallery, Plugin.LocalNotification to show local notifications from Xamarin apps, Firebase libraries to connect the application with Firebase console in cloud.

\subsection{Online Parks Booking Application pages}

Online Parks Booking application consists of many pages, these pages are explained based on application flow. Figure 10 and Figure 11 and Figure 12 shows the necessary steps to add parking.

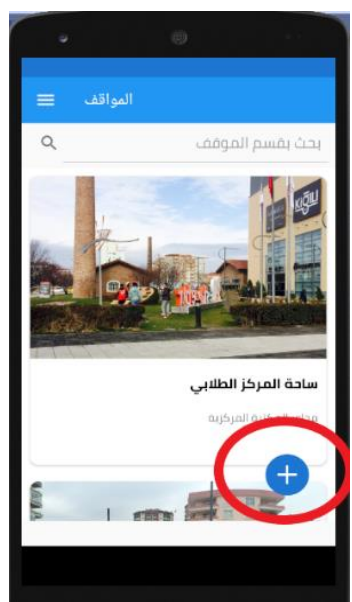

Fig. 10: Add park

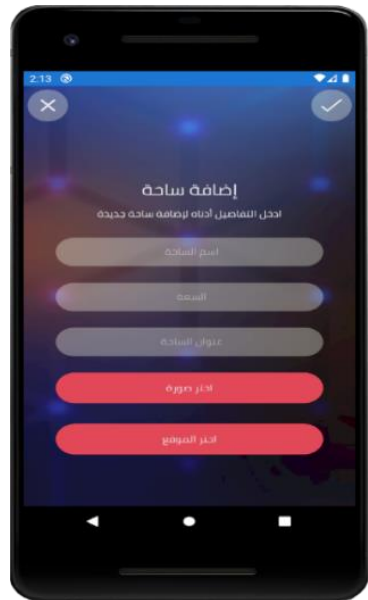

Fig. 11: Create new park

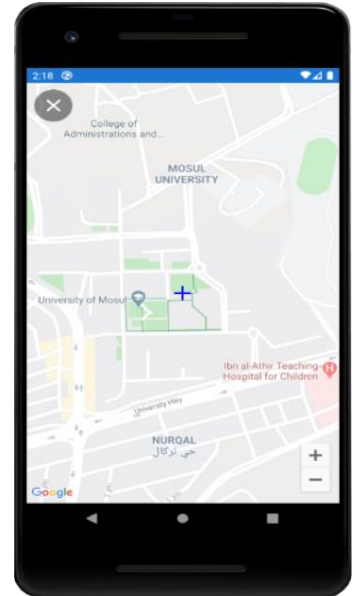

Fig. 12: Park position 
When the admin is logged in. to specify park spots for Administrative positions Figure 13 and Figure 14 and Figure 15 shows how this operation is done.

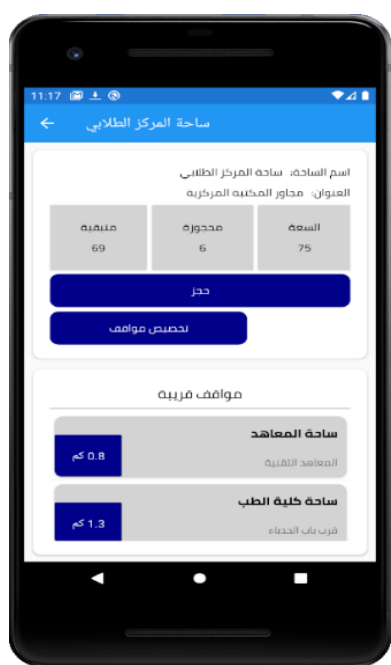

Fig. 13: Park details

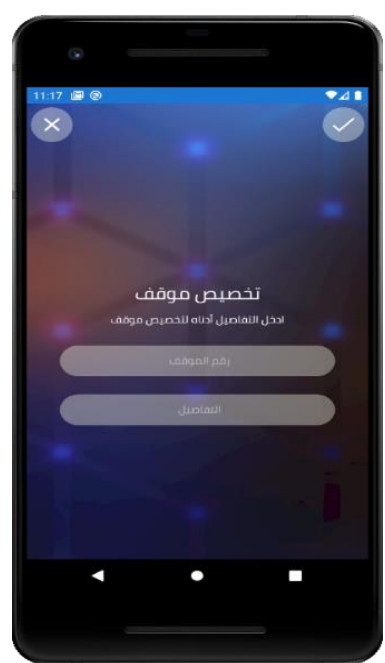

Fig. 14: Specify park

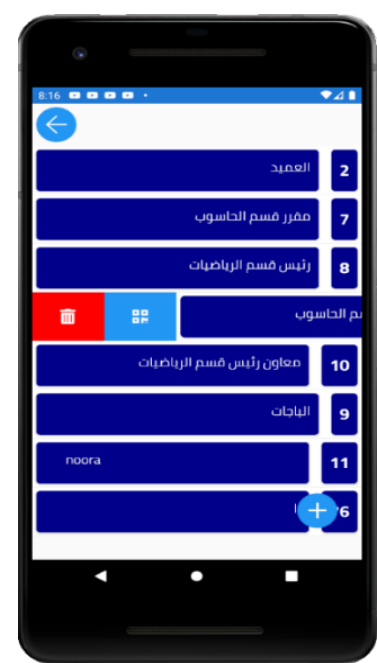

Fig. 15: Park spot options

\subsection{Reservation operation}

A park details page displays park information like park name, address, capacity, reserved parks, remaining parks, and button named Booking “ "حزך" to reserve a park online, as shown in figure 13. If the park spot is not reserved, then, an alert message will appear to the user to state that an amount of money would be deducted from user's balance to complete booking process, see figure 16. Tabbing on OK "موافق" will show a QR code, this QR code the user can use it to enter to the park. See figure 17. A timer will start down counting for 30 minutes, and another button named show QR code “عرض الرمز will show a QR code to the user within the established time limit. Figure 18 shows that.

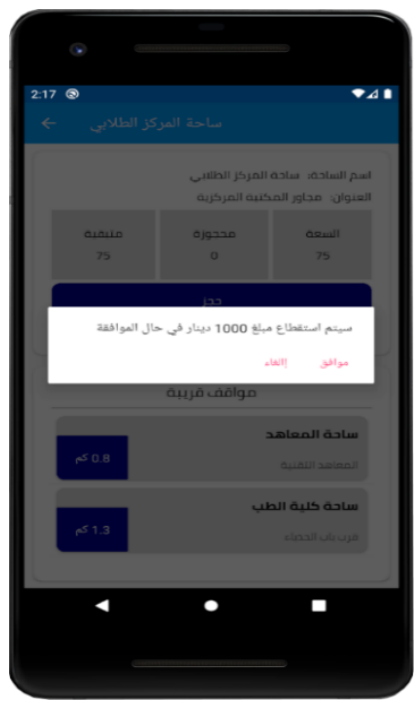

Fig 16: Deduction message

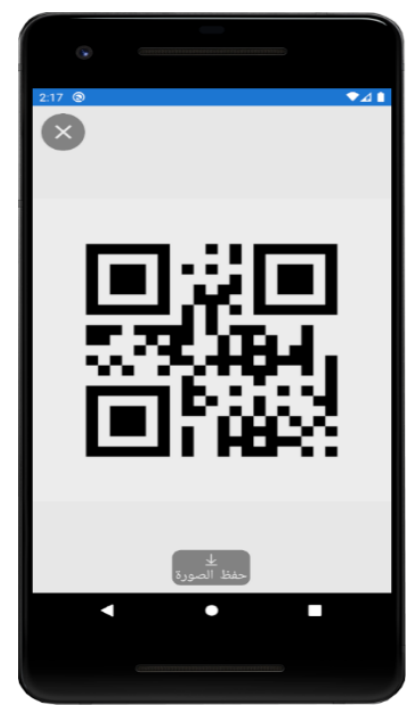

Fig 17: QR code

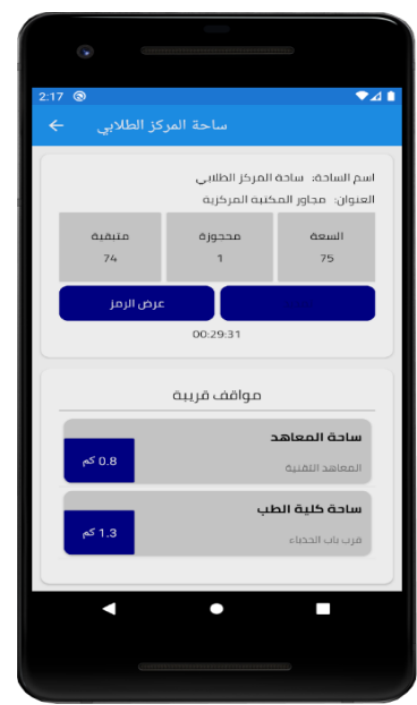

Fig 18: Park details with reservation

\subsection{Extending the reservation period}

If the user reserves a park and can't come to the park after 30 minutes, then, the reservation would be canceled and he must extend his reservation, this process will 
deduct half amount of reservation 500 IQD, and it is available through this day only, see figure 19.

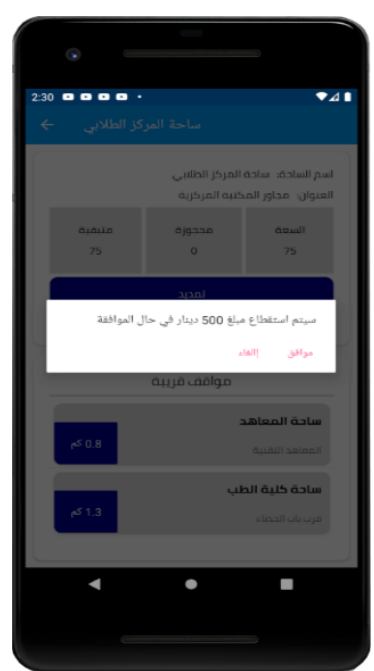

Fig 19: Deduction message

\subsection{Add balance}

The user can add balance from profile page / " contains button for adding balance to the account, see figure 22. Charge "تعبئة الرصيد" button will show dialog containing a field for inserting the charging card code, this allows the user to charge his balance, see figure 23. If the user inserts invalid code, then, a message will appear to the user tell him that the code is invalid, as shown in figure 24 . If the user inserts expired code, then, a message will appear to the user tell him that the code is expired, as shown in figure 25.

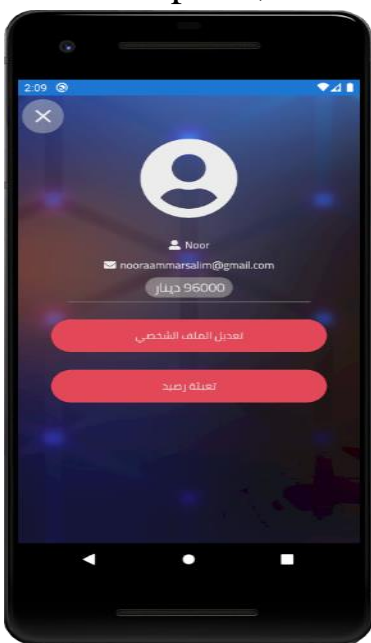

Fig 22: Profile page

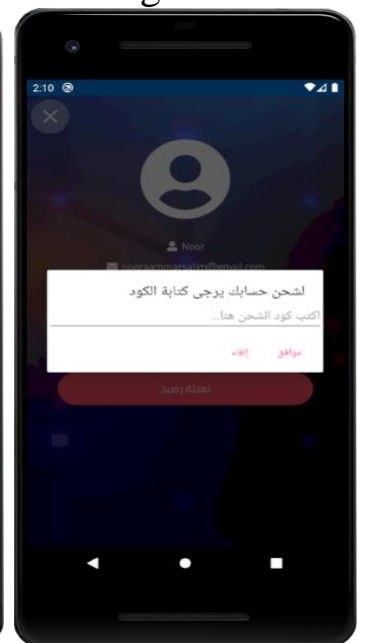

Fig 23: Balance charge Fig 24: Invalid code

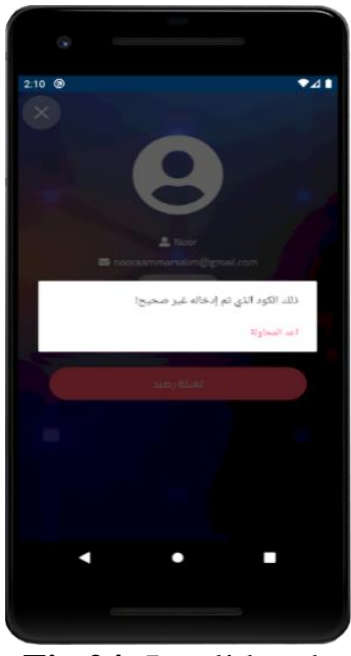

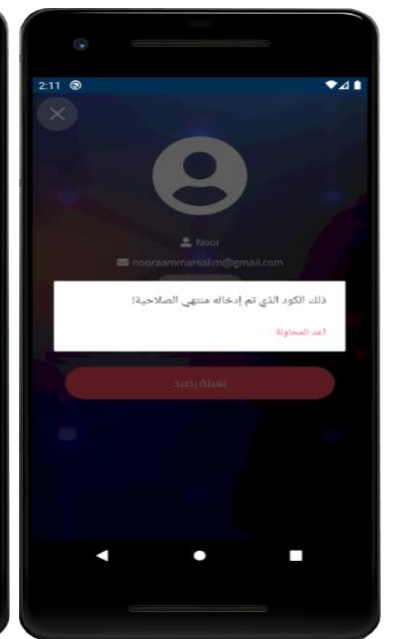

Fig 25: Expired code

\section{Results}

The system has been experimentally tested, and the results have been obtained, and we can say that results realistic, as 25 objects were tried, with 25 QR Code. Table 1 shows the test results of the entrance gate QR code and ultrasonic sensor: 
Table 1: Entrance gate QR code and ultrasonic sensor tests

\begin{tabular}{|c|c|c|}
\hline & QR code tests & Entrance gate close sensor \\
\hline Total number & 25 & 22 \\
\hline Successful tests & 22 & 22 \\
\hline unsuccessful tests & 3 & 0 \\
\hline Percentage of successful tests & $88 \%$ & $100 \%$ \\
\hline
\end{tabular}

Entrance gate will opened when the QR code reading operation is success as of 22 successful tests, so all of the unsuccessful 3 tests of the QR code was due to high brightness of the surrounding environment or low brightness of the mobile screen, therfore the entrance gate will not opened. And all of the entrance gate close sensor tests are succeeded to close the gate.

And table 2 shows the test results of the departure gate ultrasonic sensors tests for 22 attempts that successed to enter:

Table 2: Departure gate ultrasonic sensors tests

\begin{tabular}{|c|c|c|}
\hline \multirow{2}{*}{} & \multicolumn{2}{|c|}{ Departure gate } \\
\cline { 2 - 3 } & Open sensor & Close sensor \\
\hline Total number & 22 & 20 \\
\hline Successful tests & 20 & 18 \\
\hline unsuccessful tests & 2 & 2 \\
\hline Percentage of successful tests & $91 \%$ & $90 \%$ \\
\hline
\end{tabular}

We have 22 attempt to open the departure gate, 20 of the total are succeeded attempt, 2 of the attempts are failed to open the gate due to more then one reason, one of them was because of water drops on the surface of the ultrasonic sensor emitter or receiver, and the other reason because of vacuum. The close sensor attempts was 20, 18 of them are secceeded, and 2 of them are failed to close the gate due to the same reasons of the open sensor.

\section{Conclusion}

Smart phone applications are ubiquitous. Many applications have already been used in various fields to provide convenience to the user such as socializing, entertainments, education, and so on. In this work, for online parking booking was designed and implemented to provide comfortable and secure services for the Vehicle driver on their iOS and android devices depending on Firebase cloud database. There are several challenges related to firebase and smart car parking systems which have been explained and addressed by this work using Xamrin language to design and implement OPBS to enhance the booking the parking lots that rely on cloud computing. The results revealed the use of the application inventor and Firebase cloud database to implement Parks Booking as efficient with a low computational complexity. 


\section{$\underline{\text { REFERENCES }}$}

[1] Anad, M. M., Kadhim, M. H,. Mohammed M. A. and Albo baqer, K., "Followup Management System via Using Mobile Application (Follow App) in Public Sector" , Journal of Engineering and Applied Sciences, 13(1), pp. 2420-2423, (2018).

[2] Babu, CH Venkata Sai Kasturi, and Dr N. Manikanta Athuluri. "REAL TIME ADVANCE SECURITY OF PARKING SYSTEM IN IOT.", International Journal of Engineering \& Technology, (2018).

[3] Balhwan, S., Gupta, D., \& Reddy, S. R. N., "Smart Parking-A Wireless Sensor Networks Application Using IoT", In Proceedings of 2nd International Conference on Communication, Computing and Networking. Springer, Singapore, pp. 217-230, (2019).

[4] Barata, E., Cruz, L., Ferreira, J. , "Parking Problems at the UC Campus: Setting the Research Agenda", 12th WCTR, (2010).

[5] Fariza Norbaya, R. Yusnita and Norazwinawati Basharuddin, "Intelligent parking space detection system based on image processing", International Journal of Innovation, Management and Technology, 3(3), (June 2012).

[6] Marso, K., \& Macko, D., "A New Parking-Space Detection System Using Prototyping Devices and Bluetooth Low Energy Communication", International Journal of Engineering and Technology, 9(2), pp. 108-118, (2019).

[7] Mohammed, M. A., Kadhim, M. H., Fuad, A., \& Jaber, M. M., "Follow up system for directorate of scholarship and cultural relations in Iraq". 2014 International Conference on Computer, Communications, and Control Technology (I4CT). IEEE, pp. 182-187, (2014 ).

[8] Muftah, F., Fernstrom M., "Investigation of smart parking systems and their technologies", In: Thirty Seventh International Conference on Information Systems, Dublin, pp. 1-14, (2016).

[9] Pham T. N., Tsai M. F., Nguyen D. B., Dow C. R., and Deng D. J.), “A cloudbased smart-parking system based on Internet-of-Things technologies", IEEE, pp. 1581-1591, (2015).

[10] Pinto S. P., "A reservation based parking lot system to maximize occupancy and revenue", Doctoral dissertation, $\mathrm{PhD}$ Thesis Rutgers University-Graduate School-New Brunswick, (2011).

[11] Qadir, Z., Al-Turjman, F., Khan, M. A., \& Nesimoglu, T., "ZIGBEE based time and energy efficient smart parking system using IOT". In 2018 18th Mediterranean Microwave Symposium (MMS), 295-298 (2018).

[12] Saleem, Adil Ali, et al., " Review on Smart IOT Based Parking System“, International Conference on Soft Computing and Data Mining. Springer, Cham, (2020).

[13] Servo motor and motion control using digital signal https://www.sciencebuddies.org/sciencefair,projects/project_ideas/Robotics_Ser voMotors.shtml. 
[14] Shinde S., Patil A., Chavan S., Deshmukh S., and Ingleshwar S., "IoT based parking system using Google", International Conference on I-SMAC (IoT in Social, Mobile, Analytics and Cloud), IEEE, pp.634-6, (2017).

[15] Wang, Hongwei, and Wenbo He., "A reservation-based smart parking system", IEEE Conference on Computer Communications Workshops (INFOCOM WKSHPS). IEEE, (2011).

[16] Young, William, Russell G. Thompson, and Michael AP Taylor, "A review of urban car parking models", 11(1), pp. 63-84, (1991). 